\title{
A qualidade do ar e materiais particulados nos Portos do Itaqui e Ponta da Madeira - São Luís (MA)
}

Air quality and particulate materials at ltaqui
and Ponta da Madeira Ports - São Luís (MA)

\section{La calidad del aire y materiales particulados en los Puertos del Itaqui y Punta de la Madera - San Luís (MA)}

\author{
MÁrIO MASAO GOTO \\ Graduado em Engenharia Química e Mestre em Biodiversidade e Conservação \\ Vitor Otoni Costa \\ Graduado em Engenharia \\ Felipe de Souza Cologna \\ Graduado em Geologia e Mestre em Uso Sustentável dos Recursos Naturais \\ Francisco Evaldo da Silva Araújo \\ Graduado em Biologia e Mestre em Uso Sustentável dos Recursos Naturais
}

Resumo Este artigo apresenta um estudo de qualidade do ar no Porto do Itaqui e no Terminal Marítimo de Ponta da Madeira (TMPM), localizados em São Luís (MA). O objetivo foi avaliar a qualidade do ar nesses portos a partir de dados de monitoramento realizado entre os anos de 2014 e 2017, com aferição dos parâmetros Partículas Totais em Suspensão (PTS) e Partículas Inaláveis (PI). A metodologia compreendeu as etapas de caracterização física do local e contextualização dos resultados da meteorologia e da qualidade do ar. Esses resultados mostraram um atendimento parcial à regulamentação ambiental vigente. As emissões de material particulado são devidas, principalmente, ao fluxo rodoviário intenso de veículos pesados nas vias de acesso da área industrial para atendimento das atividades desenvolvidas no Porto do Itaqui e no TMPM de movimentação de granéis líquidos e sólidos em geral e de minério de ferro. A conclusão é de que, em função da crescente demanda desses portos, existe um potencial significativo de ultrapassagem dos atuais padrões de qualidade do ar e da necessidade de adoção de medidas controle para emissões de material particulado. 
Aвstract This paper presents a air quality study focusing Itaqui and Ponta da Madeira ports located at São Luís (MA). The objective was to evaluate ports' air quality based upon monitoring data between 2014 and 2017 and by measuring the indicators of Total Suspended Particles (TSP) and Inhalable Particles (IP). The methodology comprised the phases of physical local characterization and air quality and meteorological results context. The results showed a partial accomplishment of the present environmental regulation. The particulate material emission are associated, mainly, to a huge highway traffic of heavy trucks in the access routes of the industrial area in order to meet the requirements of solid and liquid bulk, mainly iron ore movements. The conclusion was that, due the growing traffic trend in these ports, there is a significant potential of overpass the present standard of air quality and so a need to take actions to control the particulate materials emissions.

Keywords: Port operation. Environmental control. Air quality. Port of Itaqui. Maritime Port of Ponta da Madeira.

Resumen Este artículo presenta un estudio de calidad del aire en el Puerto del Itaqui y en la Terminal Marítima de Ponta da Madeira (TMPM), ubicados en São Luís (MA). El objetivo fue evaluar la calidad del aire en estos puertos a partir de datos de monitoreo realizado entre los años 2014 y 2017, con la medición de los parámetros Partículas Totales en Suspensión (PTS) y Partículas Inhalables (PI). La metodología comprendió las etapas de caracterización física del local y contextualización de los resultados de la meteorología y de la calidad del aire. Estos resultados mostraron una atención parcial a la reglamentación ambiental vigente. Las emisiones de material particulado son debidas principalmente al flujo de tráfico intenso de vehículos pesados en las vías de acceso del área industrial para atender las actividades desarrolladas en el Puerto del Itaqui y en el TMPM de movimiento de graneles líquidos y sólidos en general y de mineral de hierro . La conclusión es que, en función de la creciente demanda de estos puertos, existe un potencial significativo de superación de los actuales estándares de calidad del aire y de la necesidad de adopción de medidas de control para emisiones de material particulado.

Palabras clave: Operación portuaria. Control ambiental. Calidad del Aire. Puerto del Itaqui. Terminal Marítimo de Ponta da Madeira.

\section{INTRODUÇÃO}

O objetivo principal deste trabalho é apresentar avaliação da qualidade do ar, em termos de material particulado, nas áreas compreendidas do Porto do Itaqui e do Terminal Marítimo de Ponta da Madeira (TMPM), localizadas no Distrito Industrial da cidade de São Luís no Estado do Maranhão. A partir do monitoramento dos padrões de qualidade do ar e meteorologia, fornecida por meio da rede de monitoramento pertencente à empresa Vale S.A., tornou-se possível avaliar a qualidade do ar da área industrial deste trabalho. Além dos resultados obtidos entre os anos de 2014 e 2017, são exibidas também análises de tendências do comportamento para o poluente material particulado e informações relativas às principais fontes de emissão nessa área em estudo. 
O aumento da frota veicular e do número de empresas de manufatura na cidade de São Luís/MA, nos últimos anos, contribui para a deterioração da qualidade do ar, especialmente na área do distrito industrial onde estão localizados os maiores empreendimentos dessa cidade.

As questões ambientais focam o controle da poluição, agentes de anomalias econômicas, impactos ambientais e comprometimento à saúde. Por efeito, os tomadores de decisões devem inserir métodos ou ferramentas inovadoras no processo de gestão e implementar o controle ambiental, de modo que os resultados se demonstrem em benefícios na qualidade ambiental. São necessárias ações de gestão preventivas no sentido de reduzir as decorrências da deterioração da atmosfera, garantindo a melhoria da qualidade ambiental e a proteção à saúde (CAVALCANTI, 2010, p. 4).

\section{REVISÃO BIBLIOGRÁFICA}

Diversos poluentes atmosféricos importantes encontram-se na forma de material particulado, que são partículas sólidas ou gotículas líquidas que estão suspensas no ar (MANAHAN, 2013).

A qualidade do ar é diretamente influenciada pela distribuição e intensidade das emissões de poluentes atmosféricos de origem veicular e industrial. Exercem papel fundamental, a topografia e as condições meteorológicas específicas de cada área. As emissões veiculares desempenham um papel de destaque nos níveis de poluição do ar dos grandes centros urbanos, ao passo que as emissões industriais afetam significativamente a qualidade do ar em regiões mais específicas (CETESB, 2016).

Uma das maneiras mais habituais no monitoramento da qualidade do ar é por intermédio das redes de monitoramento, que são compostas de duas ou várias estações centradas em determinada área, para mensuração de indicadores e determinação da concentração de poluentes. Neste estudo, os dados de monitoramento da qualidade do ar, em termos de poeira inalável (PI) e partículas totais em suspensão (PTS) e da meteorologia (pluviometria, direção e velocidade do vento) foram coletados da rede automatizada de qualidade do ar e meteorologia pertencente à empresa VALE S.A. e comparados com os parâmetros da legislação vigente (CONAMA 003/90). A rede automatizada de monitoramento da qualidade do ar e meteorologia (RAMQAM) foi projetada e concebida pelo estudo de inventário de fontes de emissões de emissões atmosféricas e por modelagem matemática (ECOSOFT, 2012).

\subsection{Localização do Porto do Itaqui e do Terminal Marítimo de Ponta da Madeira}

O TMPM é um porto privado pertencente à empresa Vale S.A., adjacente ao porto do Itaqui, e próximo à cidade de São Luís e defronte à Baía de São Marcos, no Maranhão, nordeste do Brasil. Destina-se principalmente à exportação de minério de ferro trazido do projeto Serra dos Carajás, no Pará (Wikipédia, 2017).

O TMPM está localizado na margem leste da Baía de São Marcos, na Ilha São Luís, situado a oito quilômetros ao sul do centro da cidade de São Luís, capital do Estado do Maranhão, 
à qual está ligado por rodovia. As coordenadas geográficas que indicam a localização do porto: Lat. 2³3'42” S Long. 44²2'44” O (ANTAQ, 2018).

O Porto do Itaqui é um porto marítimo público localizado na Baía de São Marcos, no município de São Luís, Maranhão, administrado pela Empresa Maranhense de Administração Portuária (EMAP). As atividades do porto tiveram início em julho de 1974. Uma das principais características do porto diz respeito à sua proximidade relativa com grandes centros do mercado mundial, como a Europa, América do Norte e o Canal do Panamá. As coordenadas geográficas que indicam a localização do porto são Latitude: 02³4,6’S e Longitude: $044^{\circ} 22,2^{\prime} \mathrm{W}$ (Plano Mestre Porto Itaqui, 2012).

\subsection{Demandas de crescimento do Porto do Itaqui e do TMPM}

O Porto do Itaqui tem vocação para movimentação de granéis sólidos e líquidos. Historicamente, as duas cadeias que concentram grande parte do volume são a produção de grãos - exportação de soja e milho - e a movimentação de produtos petrolíferos - importação de diesel e gasolina. Os granéis são compostos por cargas homogêneas, sem acondicionamento específico dentro das embarcações, sendo divididos em sólidos e líquidos. Os sólidos são subdivididos em minerais - produtos e subprodutos da atividade de mineração - e em vegetais commodities ligadas ao agronegócio. Os líquidos também têm subcategorias, sendo derivados de petróleo - diesel, gasolina, gás liquefeito de petróleo (GLP) etc. - petroquímicos, como a soda cáustica e biocombustíveis no caso do etanol. O Gráfico 1 mostra o histórico de movimentação do Porto do Itaqui entre 2001 e 2016 (EMAP, 2017).

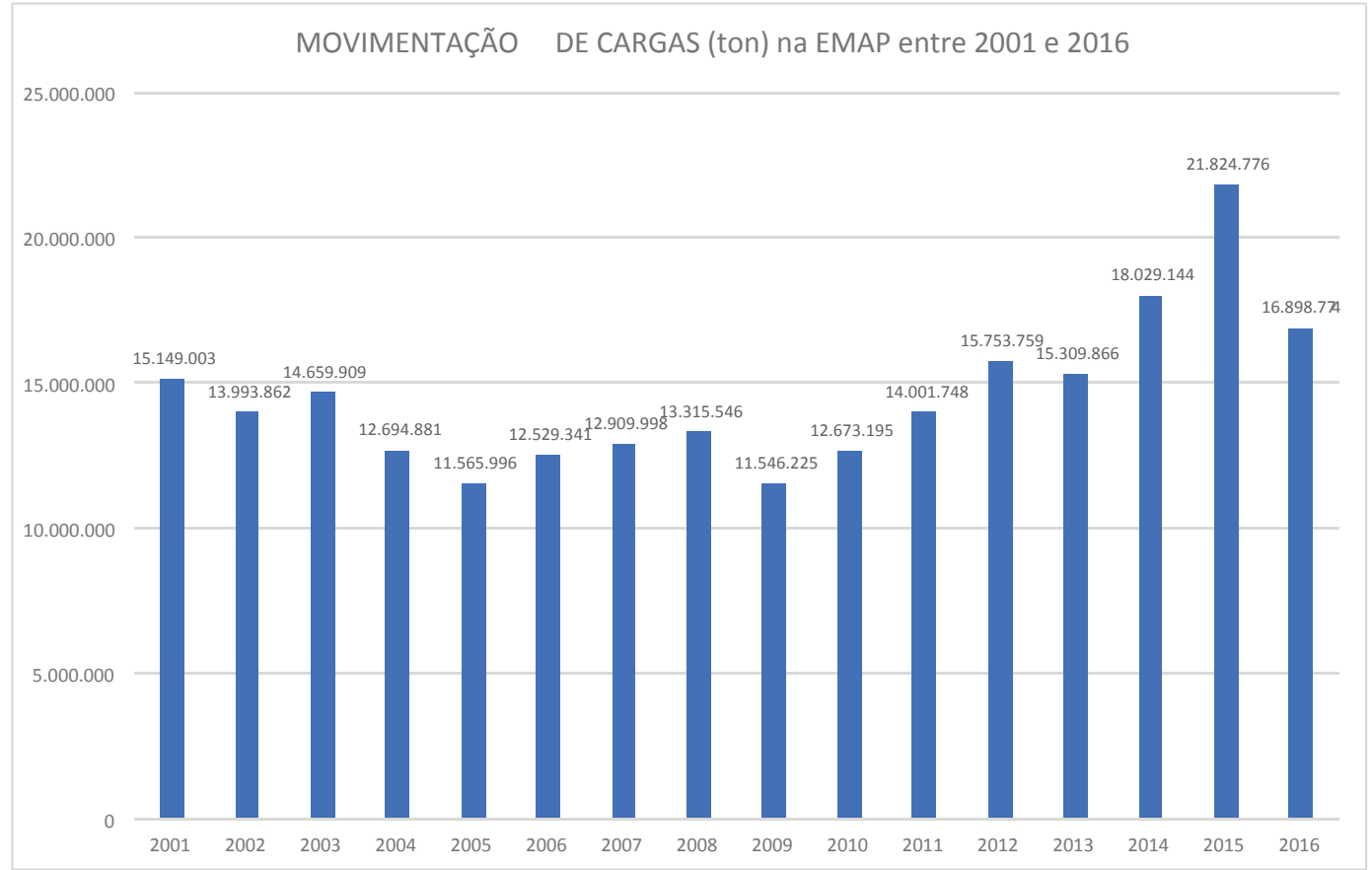

Gráfico 1 - Movimentação de cargas na Empresa Maranhense de Administração Portuária entre 2001 e 2016.

Fonte: EMAP, 2017. 
Atualmente, a EMAP possui 24 contratos de arrendamento com 15 empresas, dos quais 19 se referem a atividades operacionais de movimentação de cargas e armazenagem e, os demais, a atividades de apoio administrativo, serviços e plantas industriais. A Tabela 1 lista as empresas arrendatárias com contratos operacionais com a EMAP.

Tabela 1 - Lista das empresas arrendatárias com contratos operacionais com a EMAP.

\begin{tabular}{|c|c|c|c|}
\hline EMPRESAS & CLASSIFICAÇÕES & EMPRESAS & CLASSIFICAÇÕES \\
\hline $\begin{array}{l}\text { Amaggi \& LD Commodities } \\
\text { Terminais Portuários S.A. }\end{array}$ & $\begin{array}{c}\text { Terminal de Granéis } \\
\text { Sólidos de Origem } \\
\text { Vegetal }\end{array}$ & $\begin{array}{l}\text { Pedreiras Transpor- } \\
\text { te do Maranhão }\end{array}$ & $\begin{array}{l}\text { Terminal de Cargas } \\
\text { Gerais/Escritório }\end{array}$ \\
\hline $\begin{array}{l}\text { Companhia Nacional de Abaste- } \\
\text { cimento - CONAB }\end{array}$ & $\begin{array}{c}\text { Terminal de Granéis } \\
\text { Sólidos de Origem } \\
\text { Agropecuária }\end{array}$ & $\begin{array}{c}\text { Petrobrás - BR } \\
\text { DISTRIBUIDORA }\end{array}$ & $\begin{array}{l}\text { Terminal de Com- } \\
\text { bustíveis }\end{array}$ \\
\hline $\begin{array}{l}\text { Companhia Operadora Portuá- } \\
\text { ria do Itaqui - COPI }\end{array}$ & $\begin{array}{c}\text { Terminal de Cargas } \\
\text { Gerais }\end{array}$ & $\begin{array}{c}\text { Petrobrás Transpor- } \\
\text { tes S.A. - TRANS- } \\
\text { PETRO }\end{array}$ & $\begin{array}{l}\text { Terminal de } \\
\text { Combustíveis }\end{array}$ \\
\hline $\begin{array}{l}\text { Corredor Logística e } \\
\text { Infraestrutura S.A. }\end{array}$ & $\begin{array}{c}\text { Terminal de Granéis } \\
\text { Sólidos de Origem } \\
\text { Vegetal }\end{array}$ & Petróleo Sabbá S.A. & $\begin{array}{l}\text { Terminal de } \\
\text { Combustíveis }\end{array}$ \\
\hline $\begin{array}{l}\text { ENEVA (UTE Porto do } \\
\text { Itaqui Geração de Energia S.A.) }\end{array}$ & Granel Sólido & $\begin{array}{l}\text { SUZANO PAPEL } \\
\text { E CELULOSE }\end{array}$ & $\begin{array}{l}\text { Terminal de Granel } \\
\text { Sólido }\end{array}$ \\
\hline $\begin{array}{l}\text { Glencore Importadora e } \\
\text { Exportadora S.A. }\end{array}$ & $\begin{array}{c}\text { Terminal de Granéis } \\
\text { Sólidos de Origem } \\
\text { Vegetal }\end{array}$ & $\begin{array}{l}\text { Terminal Corredor } \\
\text { Norte S.A. }\end{array}$ & $\begin{array}{c}\text { Terminal de } \\
\text { Granéis Sólidos de } \\
\text { Origem Vegetal }\end{array}$ \\
\hline Granel Química Ltda. & $\begin{array}{l}\text { Terminal de Granel } \\
\text { Líquido }\end{array}$ & $\begin{array}{c}\text { Terminal Químico } \\
\text { de Aratu - TEQUI- } \\
\text { MAR }\end{array}$ & $\begin{array}{c}\text { Terminal de } \\
\text { Granel Líquido }\end{array}$ \\
\hline $\begin{array}{l}\text { Ipiranga Produtos de Petróleo } \\
\text { S.A. }\end{array}$ & $\begin{array}{l}\text { Terminal de Com- } \\
\text { bustíveis }\end{array}$ & $\begin{array}{l}\text { Vale S.A. (Armazém } \\
\text { de Cobre) }\end{array}$ & $\begin{array}{l}\text { Terminal de } \\
\text { Granel Sólido }\end{array}$ \\
\hline Moinhos Cruzeiro do Sul S.A. & $\begin{array}{l}\text { Terminal de Granel } \\
\text { Sólido }\end{array}$ & VLI. (Berço 105) & Berço 105 \\
\hline
\end{tabular}

Fonte: EMAP, 2017.

O TMPM representa um dos principais ativos da Vale e um dos mais importantes terminais de embarque de minério de ferro e manganês do mundo. Com as obras de ampliação para 
atender ao aumento de produção que virá com o projeto S11D, em Carajás, o terminal terá sua capacidade de embarque aumentada para 230 milhões de toneladas/ano em 2018 (VALE, 2017). O Gráfico 2 mostra o histórico de embarque do TMPM entre os anos de 1985 e 2016.

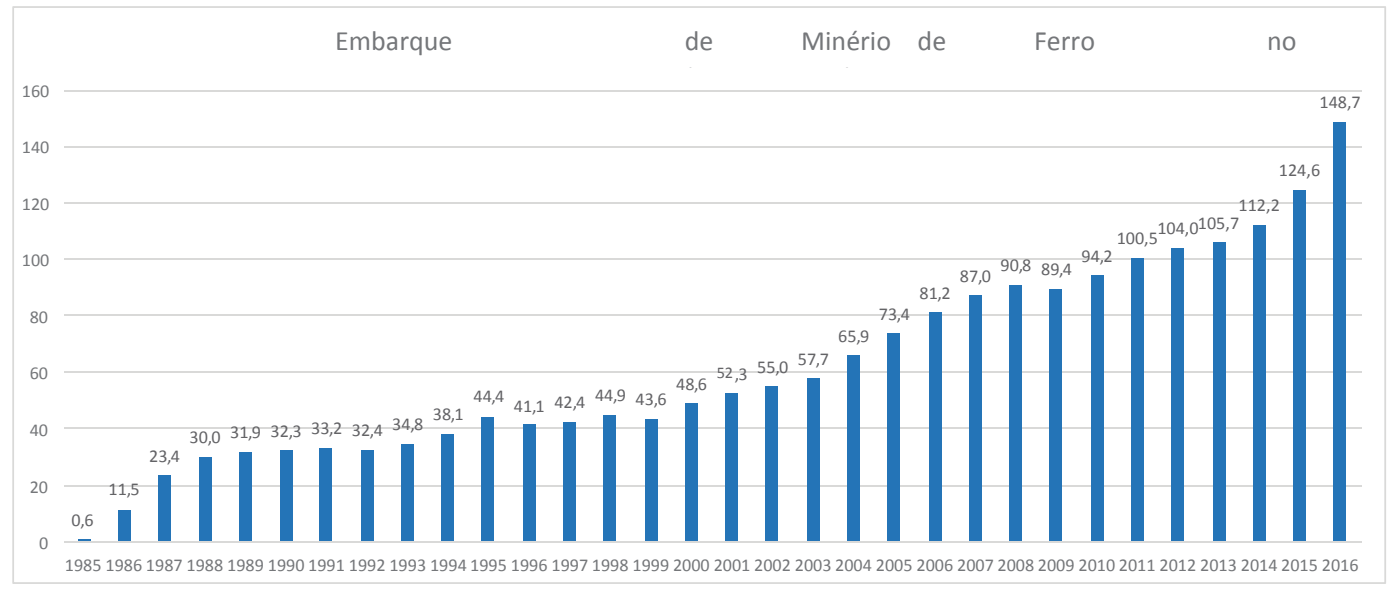

Gráfico 2 - Embarque de minério de ferro no TMPM entre 1985 e 2016.

Fonte: ANTAQ, 2016.

\subsection{Parâmetros e padrões de qualidade do ar}

A Resolução CONAMA № 3, de 28/06/1990. considera poluente atmosférico "qualquer forma de matéria ou energia com intensidade e em quantidade, concentração, tempo ou características em desacordo com os níveis estabelecidos, e que tornem ou possam tornar o ar impróprio, nocivo ou ofensivo à saúde, inconveniente ao bem-estar público, danoso aos materiais, à fauna e à flora ou prejudicial à segurança, ao uso e gozo da propriedade e às atividades normais da comunidade".

O relatório de qualidade do ar de 2016 da CETESB (página 23 de 202) indica que a determinação sistemática da qualidade do ar deve ser, por questões de ordem prática, limitada a um restrito número de poluentes definidos em função de sua importância e dos recursos materiais e humanos disponíveis. De forma geral, o grupo de poluentes consagrados universalmente como indicadores mais abrangentes da qualidade do ar é composto pelos poluentes já citados, monóxido de carbono, dióxido de enxofre, material particulado e ozônio, mais o dióxido de nitrogênio.

A razão da escolha desses parâmetros como indicadores de qualidade do ar está ligada à sua maior frequência de ocorrência e aos efeitos adversos que causam à saúde e ao meio ambiente. A Tabela 2 mostra um quadro geral dos principais poluentes considerados indicadores da qualidade do ar, bem como, suas características, quais suas origens principais e seus efeitos ao meio ambiente. Neste estudo, limitamos ao poluente Partículas Inaláveis (PI) e Partículas Totais em Suspensão (PTS). 
Tabela 2 - Fontes e características dos principais poluentes na atmosfera.

\begin{tabular}{|l|l|l|l|}
\hline Poluente & Características & Fontes Principais & $\begin{array}{l}\text { Efeitos Gerais } \\
\text { ao Meio } \\
\text { Ambiente }\end{array}$ \\
\hline $\begin{array}{l}\text { Partículas Inaláveis } \\
\text { (MP10) e Fumaça }\end{array}$ & $\begin{array}{l}\text { Partículas de material só- } \\
\text { lido ou líquido que ficam } \\
\text { suspensas no ar, na forma } \\
\text { de poeira, neblina, aeros- } \\
\text { sol, fumaça, fuligem etc. } \\
\text { Faixa de tamanho }<10 \\
\text { micra. }\end{array}$ & $\begin{array}{l}\text { Processos de combustão } \\
\text { (indústria e veículos automo- } \\
\text { tores), poeira ressuspensa, } \\
\text { aerossol secundário (forma- } \\
\text { do na atmosfera). }\end{array}$ & $\begin{array}{l}\text { Danos à ve- } \\
\text { getação, de- } \\
\text { terioração da } \\
\text { visibilidade e } \\
\text { contaminação } \\
\text { do solo e água. }\end{array}$ \\
\hline $\begin{array}{l}\text { Partículas Totais } \\
\text { em Suspensão } \\
\text { (PTS) }\end{array}$ & $\begin{array}{l}\text { Partículas de material só- } \\
\text { lido ou líquido que ficam } \\
\text { suspensas no ar, na forma } \\
\text { de poeira, neblina, aeros- } \\
\text { sol, fumaça, fuligem etc. } \\
\text { Faixa de tamanho < 100 } \\
\text { micra. }\end{array}$ & $\begin{array}{l}\text { Processos industriais, veícu- } \\
\text { los motorizados (exaustão), } \\
\text { poeira de rua ressuspensa, } \\
\text { queima de biomassa. Fontes } \\
\text { naturais: pólen, aerossol ma- } \\
\text { rinho e solo. }\end{array}$ & $\begin{array}{l}\text { Danos à ve- } \\
\text { getação, de- } \\
\text { terioração da } \\
\text { visibilidade e } \\
\text { contaminação } \\
\text { do solo e água. }\end{array}$ \\
\hline
\end{tabular}

Fonte: CETESB - Qualidade do Ar do Estado de São Paulo 2016.

Este artigo adota os padrões nacionais de qualidade do ar, fixados na Resolução CONAMA no. 03, de 28/6/1990, apresentados na Tabela 3.

Tabela 3 - Parâmetros e padrões nacionais da qualidade do ar (Adaptada da Resolução CONAMA No. 03 de 28/06/90).

\begin{tabular}{|c|c|c|c|c|}
\hline Poluente & $\begin{array}{l}\text { Tempo de } \\
\text { Amostragem }\end{array}$ & $\begin{array}{c}\text { Padrão Primário } \\
\left(\mu \mathrm{g} / \mathrm{m}^{3}\right)\end{array}$ & $\begin{array}{l}\text { Padrão Secun- } \\
\text { dário }\left(\mu \mathrm{g} / \mathrm{m}^{3}\right)\end{array}$ & $\begin{array}{c}\text { Método de } \\
\text { Medição }\end{array}$ \\
\hline \multirow{2}{*}{$\begin{array}{l}\text { partículas totais } \\
\text { em suspensão }\end{array}$} & 24 horas $^{1}$ & 240 & 150 & \multirow{2}{*}{$\begin{array}{l}\text { amostrador de } \\
\text { grandes volumes }\end{array}$} \\
\hline & $\mathrm{MGA}^{2}$ & 80 & 60 & \\
\hline \multirow{2}{*}{$\begin{array}{l}\text { partículas inalá- } \\
\text { veis }\end{array}$} & 24 horas $^{1}$ & 150 & 150 & \multirow{2}{*}{$\begin{array}{l}\text { separação iner- } \\
\text { cial/filtração }\end{array}$} \\
\hline & $\mathrm{MAA}^{3}$ & 50 & 50 & \\
\hline
\end{tabular}

1 - Não deve ser excedido mais que uma vez ao ano. 2 - Média geométrica anual. 3 - Média aritmética anual.

Para verificação do atendimento aos padrões legais de qualidade do ar, os dados mensurados foram comparados aos padrões primários estabelecidos pela Resolução CONAMA 003 de 1990. Os dados também foram correlacionados com a precipitação pluviométrica, direção e velocidade dos ventos, que são as variáveis meteorológicas de maior relevância tratando- 
-se do poluente material particulado. Foram ainda verificadas por meio de levantamento de campo, as principais fontes fixas emissoras de material particulado da área.

No ano de 2013, a partir da publicação do Decreto Estadual n ${ }^{\circ}$ 59113/2013, que estabeleceu novos padrões de qualidade do ar para o Estado de São Paulo, o Índice de Qualidade do Ar adotado pela CETESB foi reformulado (faixas, classificações e concentrações de referência dos poluentes) com base nos limites estabelecidos pela nova legislação estadual. Entretanto, tendo em vista que ainda não há em vigor legislação estadual que define novos padrões de qualidade do ar para o Estado do Maranhão, o IQA adotado pela CETESB até 2013 continua sendo utilizado como referência para este trabalho. Vide o IQA na Tabela 4.

Tabela 4 - Estrutura e Distribuição dos Índices de Qualidade do Ar (IQA).

\begin{tabular}{|c|c|c|}
\hline Fabas do IQA & $\begin{array}{l}\mathrm{PI}(<10 \mu \mathrm{M}) \\
{\left[\mu \mathrm{g} / \mathrm{m}^{\prime}\right]} \\
\text { Média } 24 \mathrm{~h}\end{array}$ & $\begin{array}{c}\text { PTS } \\
{\left[\mu g / m^{\eta}\right]} \\
\text { Média } 24 \mathrm{~h}\end{array}$ \\
\hline $\begin{array}{c}\text { Boa } \\
\geq 0 \leq 50\end{array}$ & $\geq 0 \leq 50$ & $\geq 0 \leq 80$ \\
\hline $\begin{array}{c}\text { Regular } \\
>50 \leq 100\end{array}$ & $>50 \leq 150$ & $>80 \leq 240$ \\
\hline $\begin{array}{c}\text { Inadequada } \\
>100<200\end{array}$ & $>150<250$ & $>240<375$ \\
\hline $\begin{array}{c}\text { Má } \\
\geq 200<300\end{array}$ & $\geq 250<420$ & $\geq 375<625$ \\
\hline $\begin{array}{c}\text { Péssima } \\
\geq 300\end{array}$ & $\geq 420$ & $\geq 625$ \\
\hline
\end{tabular}

Fonte: Adaptado de CETESB, com base nos padrões nacionais de qualidade do ar (Res. CONAMA nº 03/1990).

\subsection{Estações de monitoramento e parâmetros monitorados}

As estações da Rede Automática de Monitoramento da Qualidade do Ar e Meteorologia de São Luís (RAMQAM) são totalmente automatizadas, realizando medição 24 horas por dia das concentrações de poluentes na atmosfera e condições meteorológicas de superfície. As denominações das estações e os locais de instalação são apresentados na Tabela 5.

Tabela 5 - Estações de Monitoramento RAMQAM e Respectivos Parâmetros.

\begin{tabular}{|c|c|c|c|c|c|c|c|c|}
\hline \multirow{3}{*}{ Localidade } & \multirow{2}{*}{ Estação } & \multicolumn{3}{|c|}{ Qualidade do ar } & \multicolumn{5}{|c|}{ Meteorologia } \\
\cline { 3 - 10 } & & PI & PTS & DV & VV & PP & TA & UR \\
\hline \multirow{3}{*}{ São Luís } & Vila Maranhão & $\mathrm{X}$ & $\mathrm{X}$ & & & & & \\
\cline { 2 - 10 } & EMAP & $\mathrm{X}$ & $\mathrm{X}$ & $\mathrm{X}$ & $\mathrm{X}$ & $\mathrm{X}$ & $\mathrm{X}$ & $\mathrm{X}$ \\
\cline { 2 - 10 } & Bacanga & $\mathrm{X}$ & $\mathrm{X}$ & & & & & \\
\cline { 2 - 10 } & Y-Bacanga & $\mathrm{X}$ & $\mathrm{X}$ & & & & & \\
\hline
\end{tabular}

Legenda: PI - Partículas Inaláveis $(<10 \mu \mathrm{m})$; PTS - Partículas Totais em Tensão; DV - Direção do Vento; VV Velocidade do Vento; PP - Precipitação Pluviométrica; TA - Temperatura do Ar; UR - Umidade Relativa do Ar. Fonte: Autor. 
A Figura 1 apresenta a localização das estações da Rede Automática de Monitoramento da Qualidade do Ar e Meteorologia (RAMQAM) de São Luís, MA e composta pelas estações EMAP, Vila Maranhão, YBacanga e Bacanga.

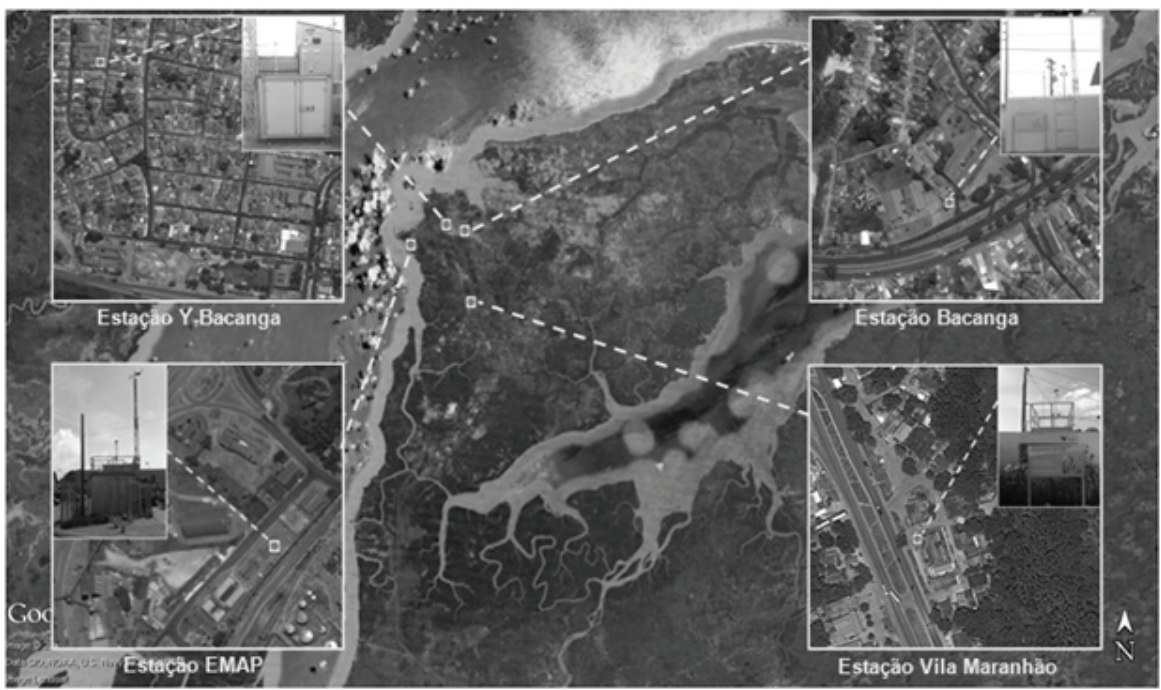

Figura 1 - Localização das Estações da RAMQAM de São Luís, MA.

Fonte: Autor.

\section{Metodologia}

O objetivo deste estudo foi avaliar a qualidade do ar do distrito industrial da cidade de São Luís, com dados de monitoramento entre os anos de 2014 e 2017, em relação aos parâmetros Partículas Totais em Suspensão (PTS) e Partículas Inaláveis (PI), comparando-os aos padrões de qualidade do ar estabelecidos pela Resolução CONAMA 003 de 1990.

O monitoramento de material particulado (PTS e PI) e meteorologia (DV, VV e Pluviometria) foi realizado pela rede automatizada (RAMQAM), pertencente à empresa Vale S.A. As estações automatizadas utilizadas foram aquelas que ficam localizadas estrategicamente na área do distrito industrial da cidade de São Luís, conforme Figura 1 do subitem 2.4. Essas estações de monitoramento são totalmente automatizadas, operando de forma contínua, 24 horas por dia, excetuando-se aquelas horas ou dias predeterminados para calibração de aparelhos ou por eventuais falhas nos mesmos. Os aparelhos usados para monitorar os parâmetros de interesse deste estudo utilizam o princípio de medição de absorção de raios beta (b) (ECOSOFT, 2012).

\section{Resultados e discussão}

\section{Parâmetros Meteorológicos:}

A partir do monitoramento realizado da DV e VV, entre os anos de 2014 e 2017, na estação EMAP, localizada no Porto do Itaqui, geramos a rosa dos ventos que apresenta uma síntese do comportamento da direção e da velocidade do vento de toda área portuária em estudo, conforme o Gráfico 3. 
Gráfico 3 - Rosa dos Ventos - Estação EMAP - entre 2014 e 2017.

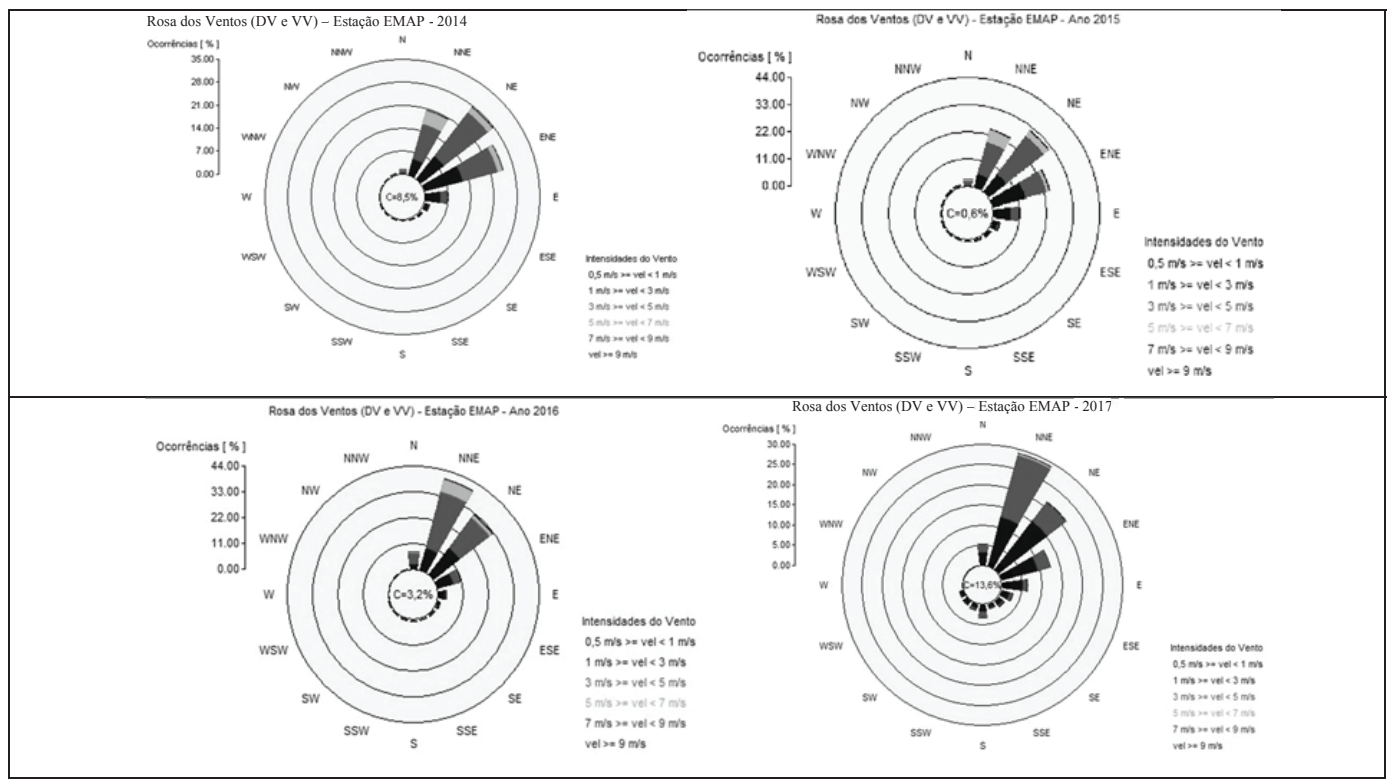

Fonte: Autor.

$\mathrm{Na}$ análise dos dados, observou-se que na estação EMAP, entre os anos de 2014 e 2017, registros de ocorrências de ventos predominantes das direções norte-nordeste (NNE), nordeste $(\mathrm{NE})$ e leste-nordeste (ENE), com calmaria entre 0,6 e 13,6\%.

\section{Precipitação Pluviométrica (PP)}

O monitoramento da pluviometria foi realizado a cada hora e os valores acumulados mensalmente de PP, entre os anos de 2014 e 2017, foram medidos na estação EMAP, conforme apresentado no Gráfico 4.

Gráfico 4 - Evolução das Medições de PP - Estação EMAP - entre 2014 e 2017.

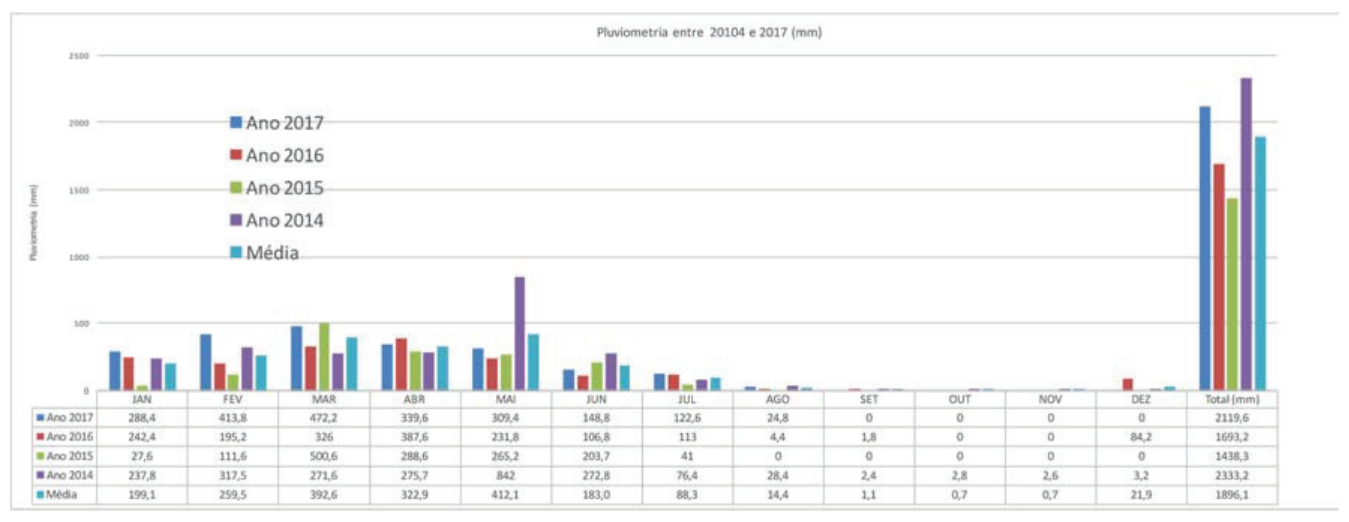

Fonte: Autor. 
A média de precipitação pluviométrica nestes últimos quatro anos foi de 1896,1 mm, sendo que $93 \%$ deste total ocorreu no primeiro semestre do ano.

\section{Qualidade do ar em termos de material particulado (PI e PTS)}

Os resultados estatísticos de PI e PTS, medidos nas estações EMAP, Bacanga, Vila Maranhão e YBacanga, entre os anos de 2014 e 2017, estão dispostos na Tabela 6.

Tabela 6 - Resultados estatísticos de PI e PTS entre os anos de 2014 e 2017.

\begin{tabular}{|c|c|c|c|c|c|c|c|}
\hline ESTAÇÃO & ANO & $\begin{array}{l}\text { Parâmetro } \\
{\left[\left[\mu \mathrm{g} / \mathrm{m}^{3}\right]\right.}\end{array}$ & $\begin{array}{l}\text { Média } \\
\text { Aritmética }\end{array}$ & $\begin{array}{c}\text { Média } \\
\text { Geométrica }\end{array}$ & $\begin{array}{l}\text { Desvio } \\
\text { padrão }\end{array}$ & $\begin{array}{l}\text { MínimoValor } \\
\text { 24horas }\end{array}$ & $\begin{array}{l}\text { Máximo Valor } \\
\text { 24horas }\end{array}$ \\
\hline \multirow[t]{8}{*}{ EMAP } & \multirow[t]{2}{*}{2014} & PTS & 92 & 74 & 62 & 18 & 206 \\
\hline & & PI & 55 & & 30 & 10 & 108 \\
\hline & \multirow[t]{2}{*}{2015} & PTS & 104 & 85 & 70 & 13 & 221 \\
\hline & & PI & 62 & & 33 & 10 & 137 \\
\hline & \multirow[t]{2}{*}{2016} & PTS & 81 & 70 & 48 & 29 & 156 \\
\hline & & PI & 51 & & 25 & 18 & 119 \\
\hline & \multirow[t]{2}{*}{2017} & PTS & 90 & 74 & 62 & 22 & 191 \\
\hline & & PI & 53 & & 32 & 12 & 93 \\
\hline \multirow[t]{8}{*}{ BACANGA } & \multirow[t]{2}{*}{2014} & PTS & 55 & 45 & 33 & 14 & 117 \\
\hline & & PI & 24 & & 16 & 6 & 54 \\
\hline & \multirow[t]{2}{*}{2015} & PTS & 65 & 56 & 37 & 9 & 138 \\
\hline & & PI & 32 & & 20 & 5 & 97 \\
\hline & \multirow[t]{2}{*}{2016} & PTS & 47 & 39 & 27 & 12 & 96 \\
\hline & & PI & 33 & & 15 & 10 & 70 \\
\hline & \multirow[t]{2}{*}{2017} & PTS & 47 & 42 & 26 & 17 & 115 \\
\hline & & PI & 33 & & 15 & 16 & 65 \\
\hline \multirow{8}{*}{$\begin{array}{l}\text { VILA } \\
\text { MARA- } \\
\text { NHÃO }\end{array}$} & \multirow[t]{2}{*}{2014} & PTS & 53 & 42 & 45 & 11 & 227 \\
\hline & & PI & 32 & & 24 & 8 & 108 \\
\hline & \multirow[t]{2}{*}{2015} & PTS & 63 & 53 & 42 & 12 & 163 \\
\hline & & PI & 34 & & 23 & 8 & 115 \\
\hline & \multirow[t]{2}{*}{2016} & PTS & 56 & 49 & 32 & 22 & 105 \\
\hline & & $\mathrm{PI}$ & 29 & & 19 & 9 & 111 \\
\hline & \multirow[t]{2}{*}{2017} & PTS & 53 & 47 & 33 & 26 & 137 \\
\hline & & PI & 32 & & 20 & 6 & 76 \\
\hline \multirow{8}{*}{$\begin{array}{l}\text { Y } \\
\text { BACANGA }\end{array}$} & \multirow[t]{2}{*}{2014} & PTS & 60 & 46 & 54 & 14 & 160 \\
\hline & & PI & 43 & & 22 & 15 & 71 \\
\hline & \multirow[t]{2}{*}{2015} & PTS & 64 & 54 & 38 & 22 & 138 \\
\hline & & PI & 39 & & 17 & 13 & 108 \\
\hline & \multirow[t]{2}{*}{2016} & PTS & 56 & 49 & 30 & 17 & 126 \\
\hline & & PI & 31 & & 18 & 10 & 90 \\
\hline & \multirow[t]{2}{*}{2017} & PTS & 53 & 45 & 30 & 18 & 102 \\
\hline & & PI & 41 & & 13 & 25 & 61 \\
\hline
\end{tabular}

Fonte: Autor.

REVISTA DE CIÊNCIA \& TECNOLOGIA • v. 21, N. 41, p. 103-1 16 • 2017 •ISSN ImpresSO: 0103-8575•ISSN Eletrônico: ISSN: 2238-1252 
A evolução dos resultados estatísticos de PTS e PI da estação EMAP, entre os anos de 2014 e 2017, pode ser analisada nos Gráficos 5 e 6.

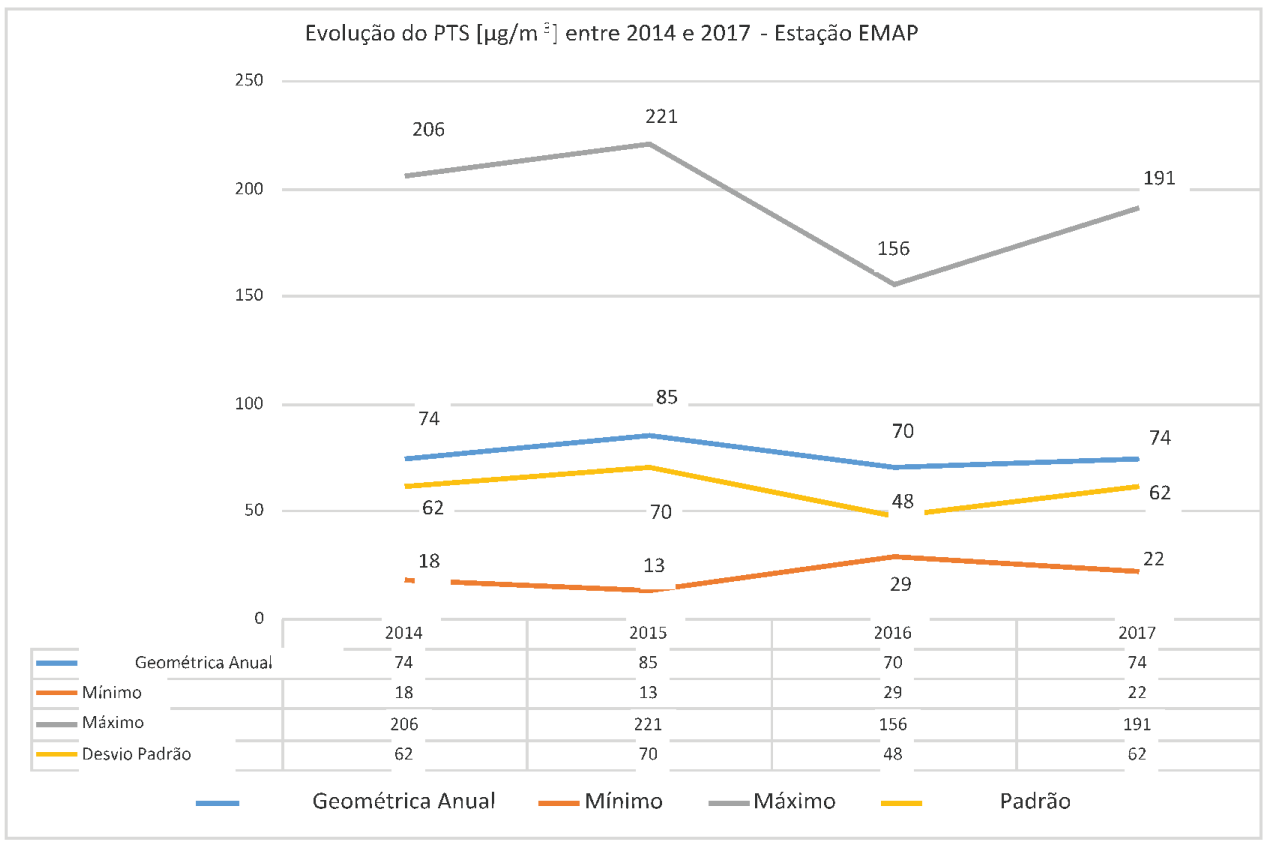

Gráfico 5 - Evolução do PTS entre 2014 e 2017 - Estação EMAP.

Fonte: Autor.

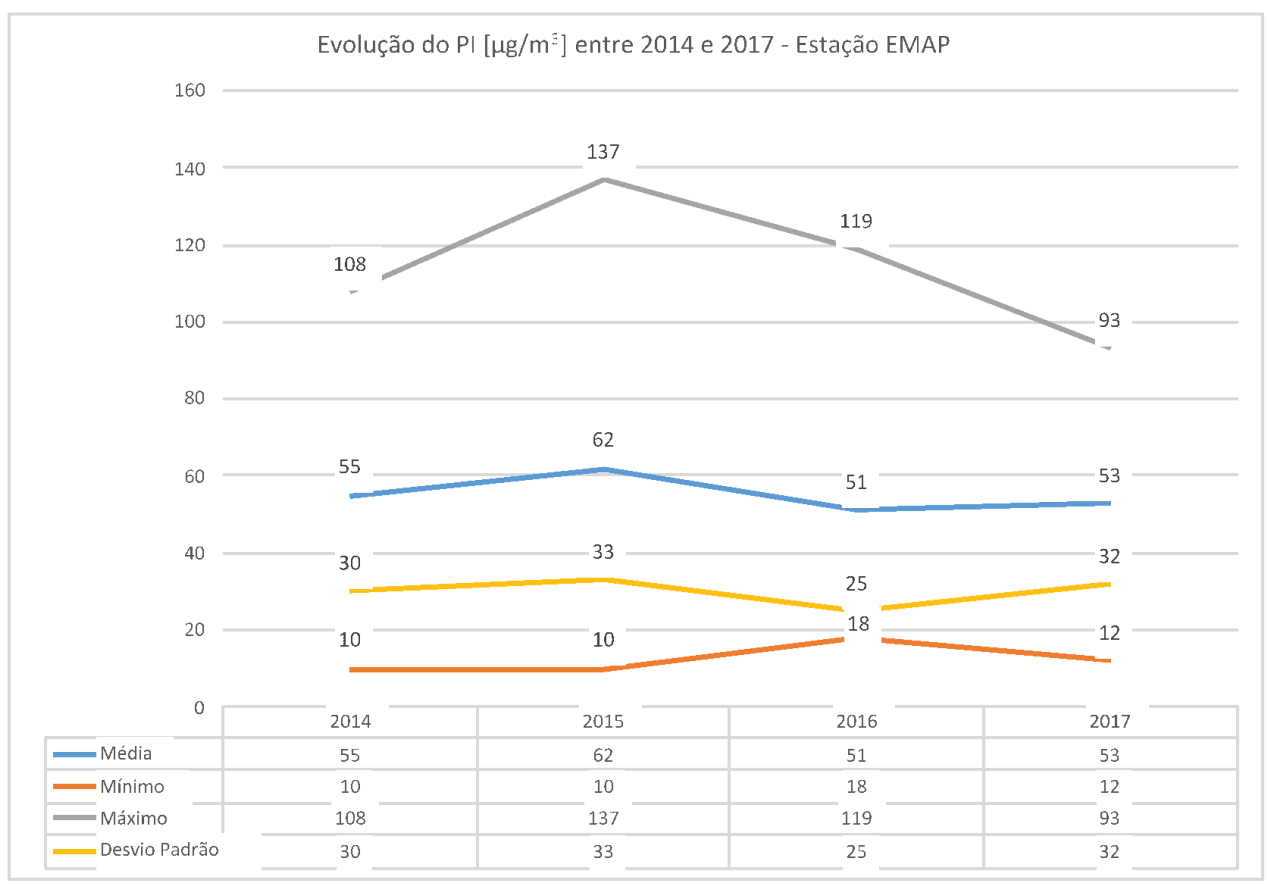

Gráfico 7 - Evolução do PI entre 2014 e 2017 - Estação EMAP.

Fonte: Autor.

114 ReviSTA DE CIÊNCIA \& TECNOLOGIA • v. 21, N. 41, P. 103-1 16 • 2017 •ISSN Impresso: 0103-8575•ISSN Eletrônico: ISSN: 2238-1252 
A Tabela 3 - Parâmetros e padrões nacionais da qualidade do ar - indica que os poluentes PTS e PI são regulamentados no Brasil pela Resolução CONAMA N. 003/1990 e, em relação ao poluente PTS, estabelece um limite máximo de $240 \mu \mathrm{g} / \mathrm{m}^{3}$ para médias de 24 horas e limite máximo de $80 \mu \mathrm{g} / \mathrm{m}^{3}$ para médias geométricas anuais. No caso do poluente PI, o limite máximo é de $150 \mu \mathrm{g} / \mathrm{m}^{3}$ para médias de 24 horas e limite máximo de $50 \mu \mathrm{g} / \mathrm{m}^{3}$ para médias anuais.

A Figura 1 - Estações da Rede Automática de Monitoramento da Qualidade do Ar e Meteorologia e parâmetros monitorados - mostra as estações Bacanga, Vila Maranhão e YBacanga, levando-se em consideração a direção predominante nordeste $(\mathrm{NE})$, localizadas a barlavento das fontes de emissão de material particulado do TMPM e Porto do Itaqui. A única estação que se encontra a sotavento das fontes de emissões é a estação EMAP e que registrou as maiores concentrações de PI e PTS do estudo.

As maiores concentrações de PI e PTS foram registradas no segundo semestre dos anos em estudo (entre 2014 e 2017), onde se registrou apenas 7\% em média do total das ocorrências de chuvas.

Nas estações Bacanga, Vila Maranhão e YBacanga, entre os anos de 2014 e 2017, os resultados das concentrações de PTS e PI 24 horas, as médias geométricas anuais de PTS e as médias aritméticas anuais de PI estavam em conformidade com a legislação vigente.

Na estação EMAP, os resultados das concentrações de PTS e PI 24 horas e as médias geométricas anuais de PTS estavam em conformidade com a legislação vigente. Contudo, para as médias aritméticas anuais de PI, em todos os anos analisados, não estavam conforme a resolução CONAMA nº. 003/1990.

\section{Considerações finais}

A pluviometria média anual, entre os anos de 2014 e 2017, foi de 1896,1 mm, sendo que em média 93\% desse total ocorreu no primeiro semestre dos anos estudados. As concentrações de PI e PTS foram influenciadas por essa sazonalidade das ocorrências de chuvas entre o primeiro e segundo semestre dos anos em estudo. No segundo semestre, as concentrações de material particulado foram maiores, sobretudo no último trimestre dos anos estudados.

Nas estações Bacanga, Vila Maranhão e YBacanga, entre os anos de 2014 e 2017, os resultados das concentrações de PTS e PI 24 horas, as médias geométricas anuais de PTS e as médias aritméticas anuais de PI estavam em conformidade com a legislação vigente. Essas estações estão localizadas a barlavento das fontes geradoras de material particulado do Porto do Itaqui e do TMPM e o IQA foi considerado como "BOA".

Na estação EMAP, os resultados das concentrações de PTS e PI 24 horas e as médias geométricas anuais de PTS, estavam em conformidade com a legislação vigente. Contudo, os resultados das médias aritméticas anuais de PI, em todos os anos analisados, não estavam conforme a Resolução CONAMA nº. 003/1990. A estação EMAP está localizada a sotavento das fontes geradoras de material particulado do Porto do Itaqui e do TMPM e o IQA foi considerado como "REGULAR".

Com vistas à preservação da qualidade do ar da região e sua manutenção em níveis adequados e visando demandas operacionais futuras crescentes, faz-se necessário a adoção de 
medidas sistemáticas de controle das emissões atmosféricas de material particulado no Porto do Itaqui e TMPM.

\section{ReFERÊNCIAS}

ANTAQ. Agência Nacional de Transportes Aquaviários. Anuário Estatístico Aquaviário 2016. Disponível em: http://www.antaq.gov.br/portal/anuarios/anuario2016/body/index. htm. Acesso em: 6 nov. 2017.

CAVALCANTI, P. M. P. S. (2010). Modelo de Gestão da Qualidade do Ar - Abordagem Preventiva e Corretiva. Tese (Doutorado). Instituto Alberto Luiz Coimbra de Pós-Graduação e Pesquisa de Engenharia, Rio de Janeiro, RJ, Brasil.

CETESB. Companhia Ambiental do Estado de São Paulo. Relatório 2016 de Qualidade do Ar da Cidade de São Paulo - Pág. 15 de 202. Disponível em: www.cetesb.sp.gov.br/ar/wp-content/uploads/sites/28/2013/12/relatorio-ar-2016.pdf. Acesso em 16 nov. 2017.

CONAMA. Resolução n. 003 de 28 de junho de 1990. Dispõe Sobre os Padrões de

Qualidade do Ar Previstos no PRONAR. Conselho Nacional de Meio Ambiente. Ministério do Meio Ambiente. Brasília-DF, 1990.

EMAP. Empresa Maranhense de Administração Portuária. Disponível em: <www.emap. ma.gov.br>. Acesso em: 10 nov. de 2017.

MANAHAN, S. E. Química Ambiental, 9. ed. Porto Alegre: Bookman, 2013.

PORTO DO ITAQUI. Plano Mestre Porto Itaqui. Disponível em: <www.portodoitaqui. ma.gov.br/pdf/plano-mestre-porto\%20do-itaqui.pdf>. Acesso em: 6 nov. 2017.

VALE S.A. Disponível em: www.vale.com/30 anos do terminal marítimo de ponta da madeira. Acesso em: 6 nov. de 2017.

Submetido em: 4-9-2018

Aceito em: 7-11-2018 